\title{
Degradation of PAI/PEI Enamel under High Temperature (Up to $400^{\circ} \mathrm{C}$ )
}

\author{
Fabrice Aymonino, Thierry Lebey, David Malec, Dominique Mary \\ LAboratoire PlAsma et Conversion d'Energie (LAPLACE), Université de Toulouse, Toulouse, France \\ Email: david.malec@laplace.univ-tlse.fr
}

How to cite this paper: Aymonino, F., Lebey, T., Malec, D. and Mary, D. (2022) Degradation of PAI/PEI Enamel under High Temperature (Up to $400^{\circ} \mathrm{C}$ ). Materials Sciences and Applications, 13, 1-21. https://doi.org/10.4236/msa.2022.131001

Received: November 25, 2021

Accepted: January 9, 2022

Published: January 12, 2022

Copyright (c) 2022 by author(s) and Scientific Research Publishing Inc. This work is licensed under the Creative Commons Attribution International License (CC BY 4.0).

http://creativecommons.org/licenses/by/4.0/

\begin{abstract}
This work deals with the understanding of the degradation of the primary insulation (PEI/PAI) of rotating machines working temporarily under high-temperature. The main domain of application of these motors is the smoke extraction either from tunnels or underground parking when a fire occurs. In such a critical situation, the internal temperature of the motor winding may reach temperatures up to $400^{\circ} \mathrm{C}$. Under such very high thermal stresses, the behaviour of the electrical insulation is not well understood. This work proposes an analysis of the decomposition gases under very high temperatures and the corresponding degradation pathway. A simple method is proposed to identify whether the insulation of such motors has been strongly damaged during the working time at very high temperatures, thus allowing estimating if it can still continue to operate.
\end{abstract}

\section{Keywords}

Polyesterimide (PEI), Polyamide-Imide (PAI), Enamel, Electrical Insulation, Rotating Machine, High Temperature, Thermal Degradation

\section{Introduction}

The research summarized in this paper is a part of a more global reflection on the potential of thermostable organic materials to be used in rotating machines working at very high temperatures [1] [2]. Indeed, in some applications, the winding temperatures of these machines may reach values higher than their insulation thermal class during the emergency (i.e., smoke extraction during the fire). This work aims to understand the influence of the temperature on the chemical structure, aging and degradation of two famous insulating materials used in the enameled wires industry: PEI (Polyesterimide) and PAI (Polyamide-imide), beyond 
their thermal classes. PEI and PAI are indeed classically used to insulate wires of such machines.

The effect of single PEI degradation under the temperatures: $180^{\circ} \mathrm{C}-250^{\circ} \mathrm{C}$ [3] [4], $400^{\circ} \mathrm{C}-700^{\circ} \mathrm{C}$ [5] and $250^{\circ} \mathrm{C}-850^{\circ} \mathrm{C}$ [6] has been already studied. Recently, new synthetic methods have been proposed to obtain PEI with high thermal stability [7]. In the same way, single PAI thermal degradation induced delamination [8] or copper ions diffusion in enamel [9] have been evaluated.

The aging of dual PEI/PAI enamels degradation under different temperatures has also been evaluated, especially the correlation between chemical structures and dielectric properties [10] [11].

The research for a correlation between the evolution of the dielectric properties and the thermal stability of these materials is one of the main objectives of this work. In the temperature range studied, i.e., $200^{\circ} \mathrm{C}-400^{\circ} \mathrm{C}$, we will attempt to evaluate the changes in structural modifications, or even degradations, measured by physicochemical analyses. These analyses should allow us to better understand the processes involved and to propose scenarios of probable degradation.

The originality of this work comes from some avenues that will also be proposed as to the preventive detection of the thermal degradation. In order to be able to extract crucial information revealing the state of degradation of the electrical insulation, we will also endeavor to propose a simple control procedure that can be applied directly to the rotating machine.

\section{Samples under Study}

This study deals with enamels used in windings of rotating machines working under temperature that may reach $200^{\circ} \mathrm{C}-220^{\circ} \mathrm{C}$ at hot spots. Enameled wire insulated by a double layer PEI (inner layer)/PAI (outer layer) are often used in this temperature range. PEI sticks well to copper and PAI reinforces the thermal resistance, so it is a good compromise [12].

\subsection{Synthesis of PEI}

It is generally an isophthalic or/and terephthalic polyester of ethylene glycol and glycerol in solution in an aromatic/cresylic solvent mixture. A portion of trimellitic anhydride is introduced into the acid part which, together with a diisocyanate, forms an imide function. The formulation is accompanied by additives such as phenolic resins and crosslinking catalysts (usually titanate based). The composition of di- and tri-functional alcohol, aromatic and sometimes aliphatic acid (adipic acid) and imide function (isocyanate level) conditions the final properties of the enamel: adhesion, flexibility, thermal class, weldability... The different monomers are listed and gathered below according to their chemical family.

Acids: 


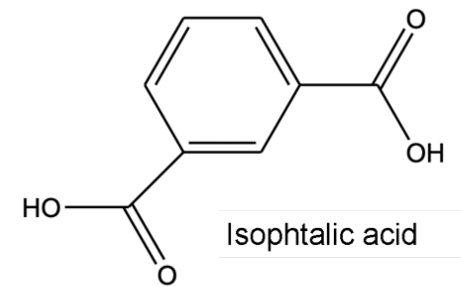<smiles>O=C(O)CCCCC(=O)O</smiles>

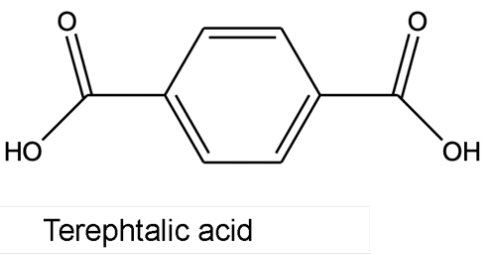<smiles>O=C(O)c1ccc2c(c1)C(=O)OC2=O</smiles>

Alcohols:

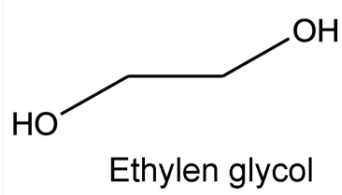

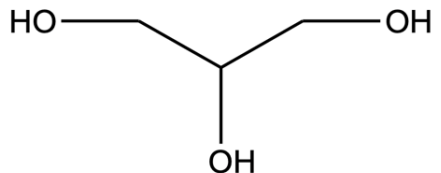

Glycerol

Isocyanate:

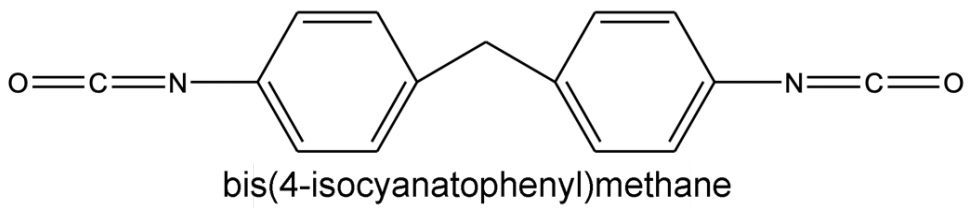

THEIC:<smiles>O=c1n(CCO)c(=O)n(CCO)c(=O)n1CCO</smiles>

The reaction of all these compounds in different proportions (Acids, Alcohols, Isocyanate) allows the formation of the esterimide function. The presence of trifunctional compounds (triol) makes this material a crosslinked polymer. To in- 
crease the resistance in tension and the plasticity, the PEI is reinforced by the addition of Tri Hydroxyethyl Isocyanurate (THEIC). The introduction of THEIC complicates the structure of the enamel. During the polycondensation reaction, $\mathrm{CO}_{2}$ and $\mathrm{H}_{2} \mathrm{O}$ are released. In the end, the PEI having the following theoretical composition is obtained (Figure 1).

PEI is an infusible and not very hydrophilic. Its dielectric strength (at $50 \mathrm{~Hz}$ ) is of about $18 \mathrm{kV} / \mathrm{mm}$ for $1 \mathrm{~mm}$ (manufacturer data: Dupont; on twisted pair, increase in diameter due to enamel: $66 \mu \mathrm{m}$ ) and its dielectric constant is ranging<smiles>O=C=Nc1ccc(Cc2ccc(N=C=O)cc2)cc1</smiles><smiles>O=C(O)CCCCC(=O)O</smiles><smiles>O=C(O)c1ccc2c(c1)C(=O)OC2=O</smiles><smiles>OCC(O)CO</smiles><smiles>O=C(O)c1cccc(C(=O)O)c1</smiles><smiles>COCCOC(=O)c1ccc(C(=O)OCCn2c(=O)n(CCOC(=O)c3cccc(C(=O)OCCOC(=O)CCCCC(=O)OCC(COC)OC)c3)c(=O)n(CCOC(=O)c3ccc4c(c3)C(=O)N(c3ccc(Cc5ccc(N6C(=O)c7ccc(C(C)=O)cc7C6=O)cc5)cc3)C4=O)c2=O)cc1</smiles>

Figure 1. PEI synthesis. 
from 3.1 to 3.3 .

\subsection{Synthesis of PAI}

Polyamide-imides are the product of the reaction of a di-isocyanate such as di-phenyl methane di-isocyanate with trimellitic anhydride. The reaction is carried out in a reactor in a solvent, $\mathrm{N}$-methyl-2-pyrrolidone (NMP) and is accompanied by the release of $\mathrm{CO}_{2}$.

The PAI synthesis schema shows a simpler constituent unit of the polymer than that of PEI (Figure 2). The dielectric constant of the material considered at $1 \mathrm{MHz}$ is ranging from 3.9 to 5.4 and its dielectric strength is high $(22.8 \mathrm{kV} / \mathrm{mm}$ for a $1 \mathrm{~mm}$ sample, manufacturer data: Torlon). It is hygroscopic: it can indeed absorb up to $1.7 \%$ of water by mass. This property is linked to the polar functions present in its structure.

Studied enamel chips and powder are obtained by peeling enameled wires on stainless steel plates. These powders and chips will be used to carry out physicochemical measurements.

\section{Chromatography and Mass Spectroscopy Coupling}

ATG was used to determine the degassing temperature of the decomposition products (temperature rising rate: $1^{\circ} \mathrm{C} / \mathrm{min}$ ). A Diamond TG/ATG Perkin Elmer Instruments has been used to perform ATG measurements. To perform such measurements, a small quantity of powder is sufficient, i.e.: $\leq 10 \mathrm{mg}$. These few milligrams are placed in the crucibles which are attached to a hanger and introduced into the furnace. The hanger is connected to the counterweight by a flail. The atmosphere is controlled by a gas sweep (in our study air or helium). Other samples are then placed in an oven which performs successive temperature stages of 15 minutes in order to allow the recovery of the gases in sufficient concentration. The gases are first recovered in an adsorbent (unique for each temperature range) then desorbed in a chromatographic column. Chromatography separates the gas mixture and mass spectroscopy identifies decomposition products. The device

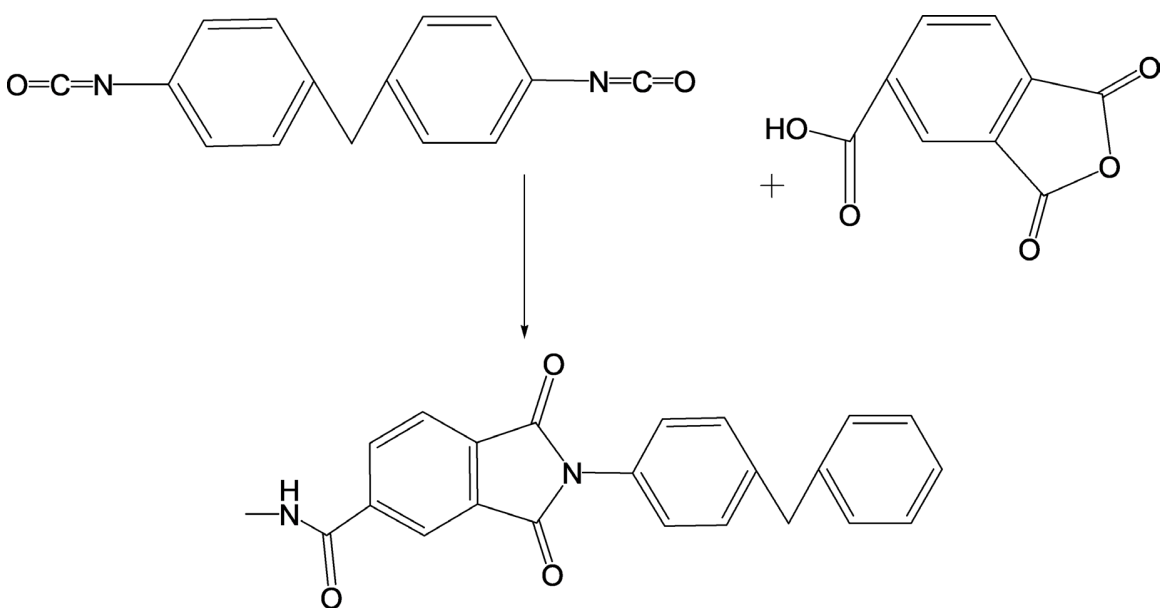

Figure 2. PAI synthesis. 
used for gas recovery is shown schematically in the following Figure 3.

Gas chromatography measurements coupled with mass spectroscopy were performed with heating under different atmospheres, one in an inert medium (Helium) and the other one in the presence of oxygen (air). An example of a chromatogram is given in Figure 4 . The different peaks are identified by mass spectroscopy (Figure 5).

The identification of these peaks by temperature range and under different atmospheres allowed us to separate the different degradation products according to their thresholds of appearance (Figure 4). We were therefore able to establish

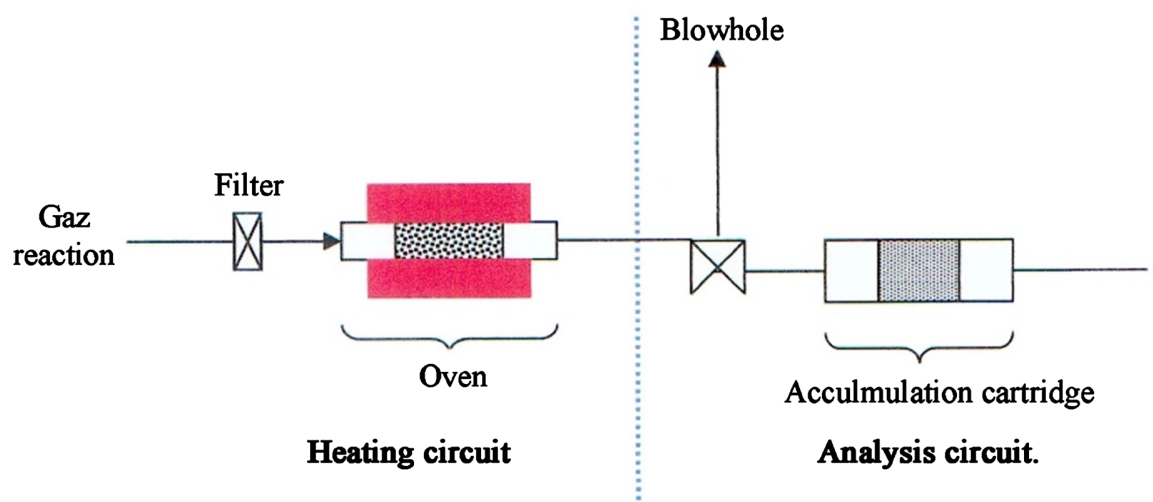

Figure 3. Diagram of recovery of decomposition gases.

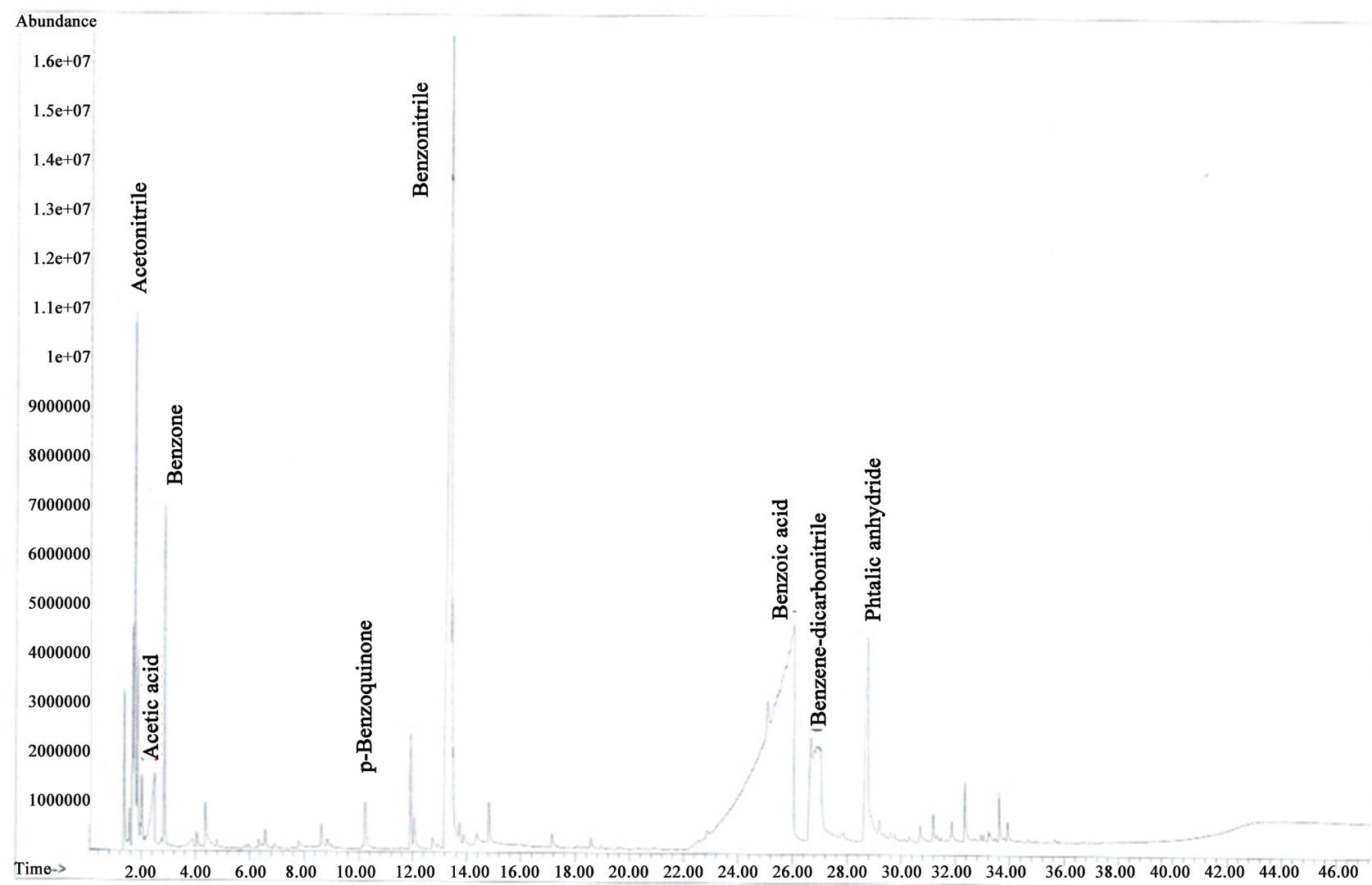

Figure 4. PAI/PEI chromatogram in air at $\mathrm{T}=400^{\circ} \mathrm{C}$. 

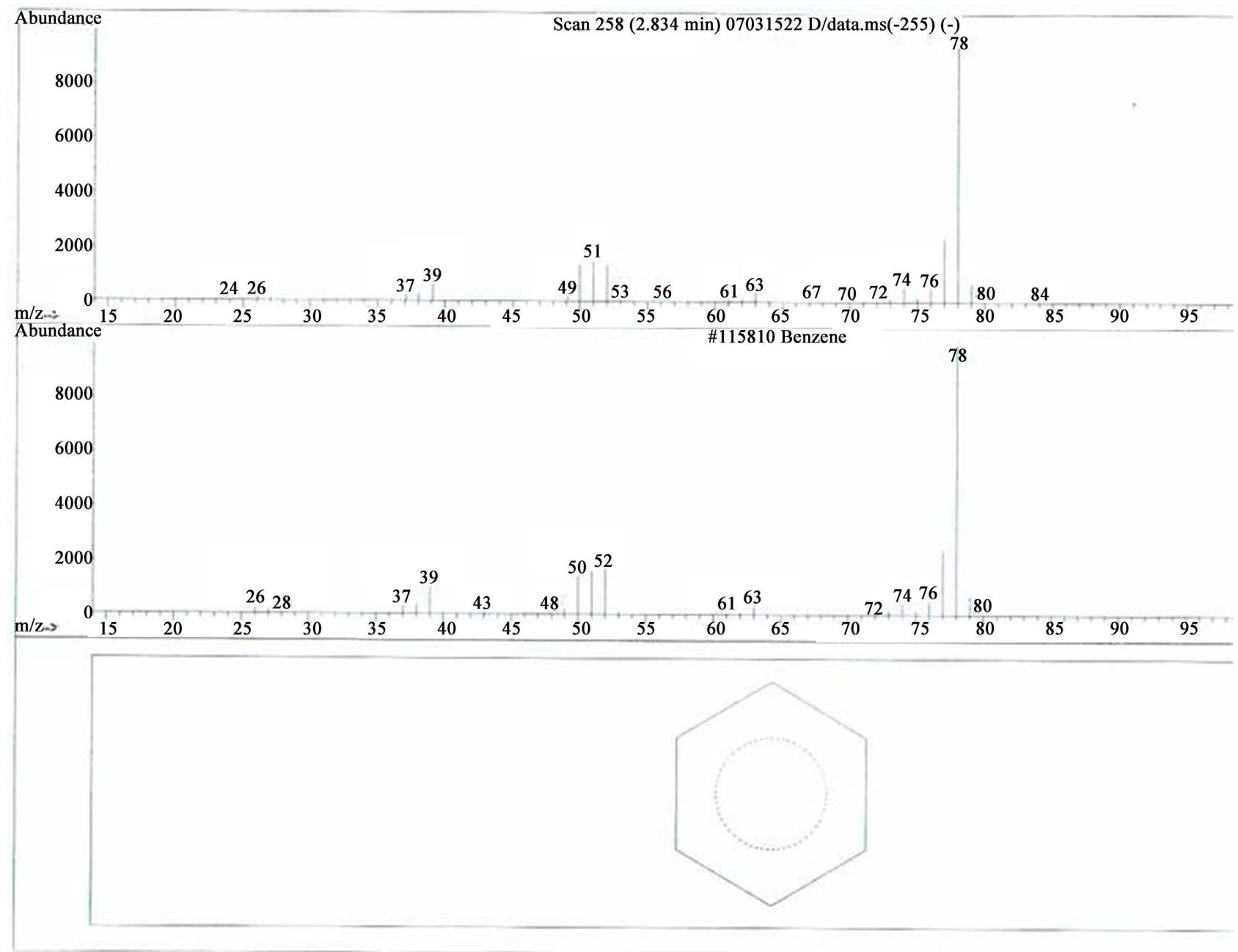

Figure 5. PAI/PEI mass spectrum.

preferential reaction diagrams for each medium. The reactions are multiple, but nevertheless the main reaction proposals have been gathered below, by separating the two analysis media (helium and air).

These degradations contribute to the loss of mass of the sample because the products formed are in the gaseous state at these temperatures. During these degradations, radicals (homolytic scissions) may appear. These compounds being very reactive, they recombine rapidly either with each other or by tearing an $\mathrm{H}$-atom on another polymer chain.

We have reported below the main degradation products identified by mass spectrometry at different temperature levels, for the different atmospheres: inert (Table 1) and oxidizing (Table 2). The decomposition reactions leading to the identified products will be explained in Section 4.

The degradation products in an inert medium are not the same as those present in an oxidizing medium. Oxygen therefore changes the degradation reaction patterns. The appearance and disappearance of degradation products can respond to two different phenomena: the first one is the activation of the 
Table 1. Main degradation products identified in helium $(\mathrm{X}=$ present, $\mathrm{Tr}=$ retention time $)$.

\begin{tabular}{|c|c|c|c|c|c|c|c|c|c|}
\hline $\operatorname{Tr}$ & Identification & $250^{\circ} \mathrm{C}$ & $300^{\circ} \mathrm{C}$ & $350^{\circ} \mathrm{C}$ & $400^{\circ} \mathrm{C}$ & $450^{\circ} \mathrm{C}$ & $500^{\circ} \mathrm{C}$ & $550^{\circ} \mathrm{C}$ & $600^{\circ} \mathrm{C}$ \\
\hline 2.00 & Isocyanateethyle & & & & $\mathrm{X}$ & $\mathrm{X}$ & & & \\
\hline 2.57 & Acetiqueacid & & & $\mathrm{X}$ & $\mathrm{X}$ & & & & \\
\hline 2.83 & Benzene & & & $\mathrm{X}$ & $\mathrm{X}$ & $\mathrm{X}$ & $\mathrm{X}$ & $\mathrm{X}$ & $\mathrm{X}$ \\
\hline 4.78 & Toluene & & $\mathrm{X}$ & $\mathrm{X}$ & $\mathrm{X}$ & $\mathrm{X}$ & $\mathrm{X}$ & $\mathrm{X}$ & $\mathrm{X}$ \\
\hline 8.14 & P Xylene & & & & & $\mathrm{X}$ & $\mathrm{X}$ & $\mathrm{X}$ & $\mathrm{X}$ \\
\hline 8.98 & Styrene & & & $\mathrm{X}$ & $\mathrm{X}$ & $\mathrm{X}$ & $\mathrm{X}$ & $\mathrm{X}$ & $\mathrm{X}$ \\
\hline 9.05 & M Xylene & $\mathrm{X}$ & & & & & & & \\
\hline 12.04 & Benzaldehyde & $\mathrm{X}$ & $\mathrm{X}$ & $\mathrm{X}$ & $\mathrm{X}$ & & & & \\
\hline 12.99 & Aniline & & & & & $\mathrm{X}$ & $\mathrm{X}$ & $\mathrm{X}$ & $\mathrm{X}$ \\
\hline 13.27 & Benzonitrile & & & $\mathrm{X}$ & $\mathrm{X}$ & $\mathrm{X}$ & $\mathrm{X}$ & $\mathrm{X}$ & $\mathrm{X}$ \\
\hline 15.69 & Benzylic alcohol & $\mathrm{X}$ & $\mathrm{X}$ & & & & & & \\
\hline 17.20 & 2-Methyl benzonitrile & & & & & & $\mathrm{X}$ & $\mathrm{X}$ & $\mathrm{X}$ \\
\hline 17.52 & P Aminotoluene & & & & & & $\mathrm{X}$ & $\mathrm{X}$ & $\mathrm{X}$ \\
\hline 18.25 & 4-Methyl benzonitrile & & & & & & & $\mathrm{X}$ & $\mathrm{X}$ \\
\hline 18.88 & Methylbenzonitrile & & & & & $\mathrm{X}$ & $\mathrm{X}$ & $\mathrm{X}$ & $\mathrm{X}$ \\
\hline 25.66 & Acide benzoïque & & & & $\mathrm{X}$ & $\mathrm{X}$ & $\mathrm{X}$ & $\mathrm{X}$ & \\
\hline 26.61 & 1,2-Benzene-dicarbonitrile & & & & & $\mathrm{X}$ & $\mathrm{X}$ & $\mathrm{X}$ & \\
\hline 28.66 & Phtalic anhydrides & & & $\mathrm{X}$ & $\mathrm{X}$ & & & & \\
\hline 29.17 & Benzene-dicarbo-nitrilisomer & & & & & & & $\mathrm{X}$ & \\
\hline 32.54 & Diphenylmethane & & & & & & & $\mathrm{X}$ & $\mathrm{X}$ \\
\hline
\end{tabular}

Table 2. Main degradation products identified in air $(\mathrm{X}=$ present; $\mathrm{Tr}=$ retention time $)$.

\begin{tabular}{|c|c|c|c|c|c|c|c|c|c|}
\hline $\operatorname{Tr}$ & Identification & $250^{\circ} \mathrm{C}$ & $300^{\circ} \mathrm{C}$ & $350^{\circ} \mathrm{C}$ & $400^{\circ} \mathrm{C}$ & $450^{\circ} \mathrm{C}$ & $500^{\circ} \mathrm{C}$ & $550^{\circ} \mathrm{C}$ & $600^{\circ} \mathrm{C}$ \\
\hline 1.73 & Acetonitrile & & & $\mathrm{X}$ & $\mathrm{X}$ & $\mathrm{X}$ & & & \\
\hline 2.42 & Aceticacid & & $\mathrm{X}$ & $\mathrm{X}$ & $\mathrm{X}$ & & & & \\
\hline 2.83 & Benzene & & & $\mathrm{X}$ & $\mathrm{X}$ & $\mathrm{X}$ & $\mathrm{X}$ & $\mathrm{X}$ & $\mathrm{X}$ \\
\hline 4.78 & Toluene & & $\mathrm{X}$ & & & & & & \\
\hline 10.23 & $\mathrm{P}$ benzoquinone & & $\mathrm{X}$ & $\mathrm{X}$ & $\mathrm{X}$ & & & & \\
\hline 11.92 & Phenylisocyanate & & & $\mathrm{X}$ & $\mathrm{X}$ & & & & \\
\hline 12.04 & Benzaldehyde & $\mathrm{X}$ & $\mathrm{X}$ & $\mathrm{X}$ & $\mathrm{X}$ & & & & \\
\hline 13.18 & Benzonitrile & & & $\mathrm{X}$ & $\mathrm{X}$ & $\mathrm{X}$ & $\mathrm{X}$ & $\mathrm{X}$ & $\mathrm{X}$ \\
\hline 13.39 & Phenol & & & $\mathrm{X}$ & & & & & \\
\hline 15.87 & Benzylic alcohol & $\mathrm{X}$ & $\mathrm{X}$ & & & & & & \\
\hline 23.96 & Benzoicacid & $\mathrm{X}$ & $\mathrm{X}$ & $\mathrm{X}$ & $\mathrm{X}$ & $\mathrm{X}$ & $\mathrm{X}$ & $\mathrm{X}$ & \\
\hline 26.66 & 1,2-Dicarbonitrile-benzene & & & $\mathrm{X}$ & $\mathrm{X}$ & $\mathrm{X}$ & $\mathrm{X}$ & $\mathrm{X}$ & $\mathrm{X}$ \\
\hline 28.75 & Phtalic anhydride & & $\mathrm{X}$ & $\mathrm{X}$ & $\mathrm{X}$ & & & & \\
\hline 29.17 & Dicarbo-benzene nitrile isomer & & & & & $\mathrm{X}$ & $\mathrm{X}$ & & \\
\hline
\end{tabular}


degradation reaction by temperature, the second one is the exhaustion of function. We can notice that, whatever the reaction medium, the first degradation products result from the degradation of the ester function (first extremum identified in the DTG curves of the PEI and PAI/PEI). The carbonitrile function, degradation of the imide or the amide function, only appears significantly from higher temperatures (Figure 6). The abundance of these compounds is also

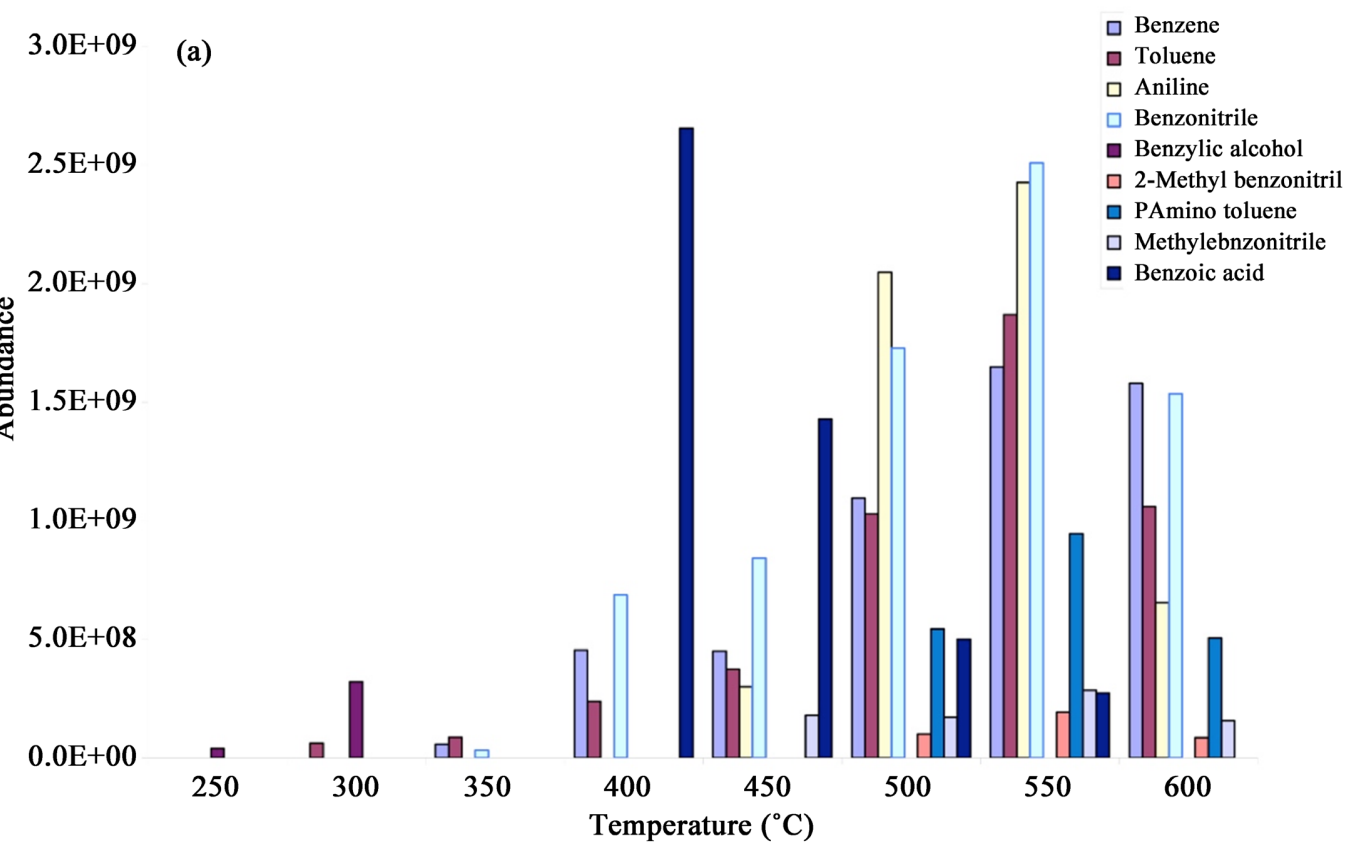

$1 \mathrm{E}+10$ (b)

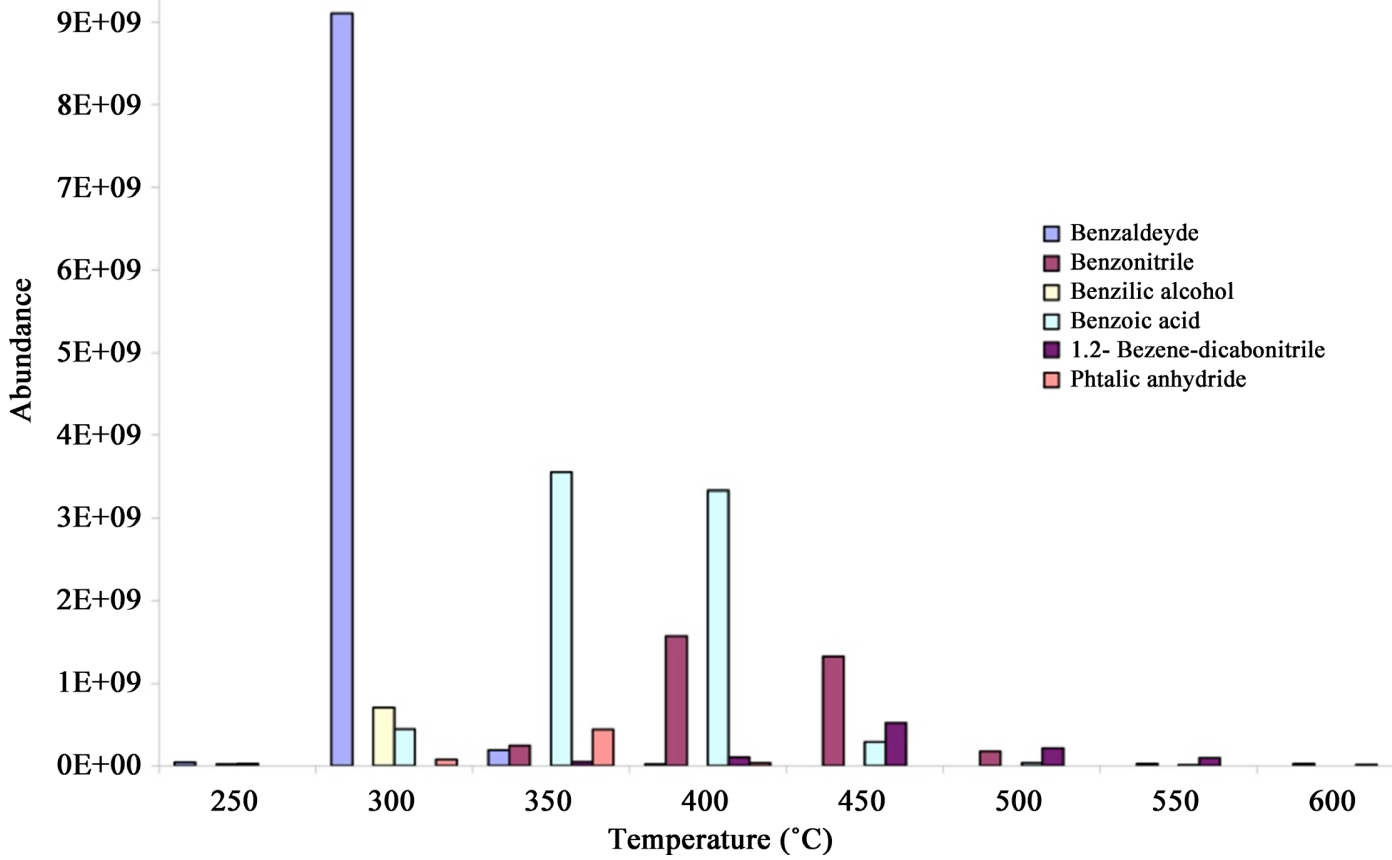

Figure 6. Abundance of degradation products of PAI/PEI versus temperature and atmosphere (up: in helium, down: in air). 
important, it will separate the main degradation reactions from the secondary ones. Only the degradation products in large quantities are shown in Figure 6.

These degradation products provide information on the interaction of oxygen with materials. Its presence is also felt in the stability of functions. Indeed, by comparing the degradation products common to the two media (inert and oxidizing), we notice that the temperatures of appearance of these products are slightly higher in an inert medium. Oxygen therefore, even indirectly, has a negative impact on the stability of these materials.

\section{Proposed PAI/PEI Degradation Pathways}

\subsection{Without Oxygen}

In an inert medium (analysis in helium), the degradation reactions are reactions of chain scission and rearrangements. The main products of these decompositions are collected in Table 1 .

Toluene comes from the cleavage at the level of $\mathrm{CH}_{2}$ present between the two aromatic rings resulting from bis(4-isocyanatophenyl)methane (Figure 7).

The scission occurs because the temperature provides enough energy to break the $\mathrm{C}-\mathrm{C}$ bond between the aromatic rings. The radicals formed then react and acquire the $\mathrm{H}$ to stabilize. Benzyl alcohol and benzoic acid come from the degradation of the ester function (Figure 8). During this degradation, we can note a gas release of $\mathrm{CO}_{2}$ and $\mathrm{CO}$.

The temperature allows the $\mathrm{C}-\mathrm{O}$ bond to break, which can lead to the loss of $\mathrm{CO}$ or $\mathrm{CO}_{2}$, depending on the location of the break. Usually, the weak point in the polymer chain is at the oxygen atom. As this has two non-binding doublets,

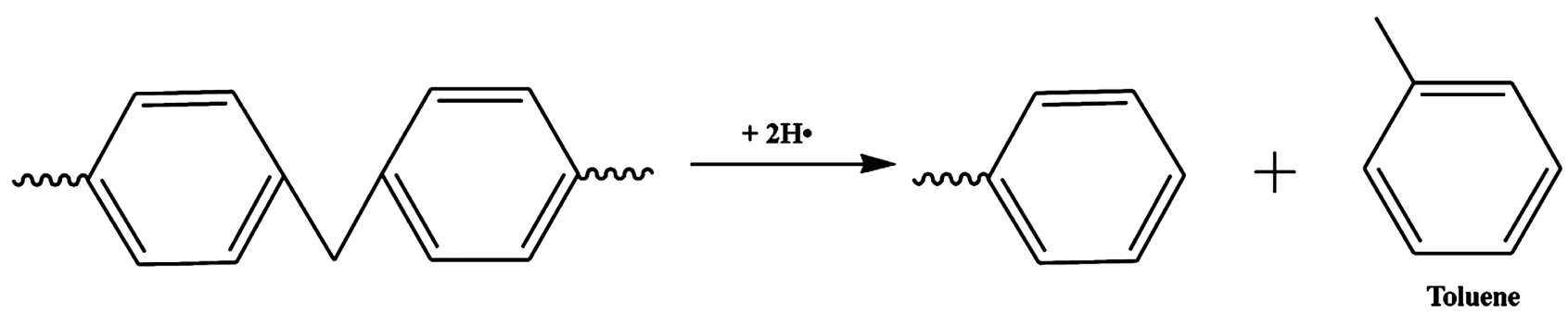

Figure 7. Toluene formation.
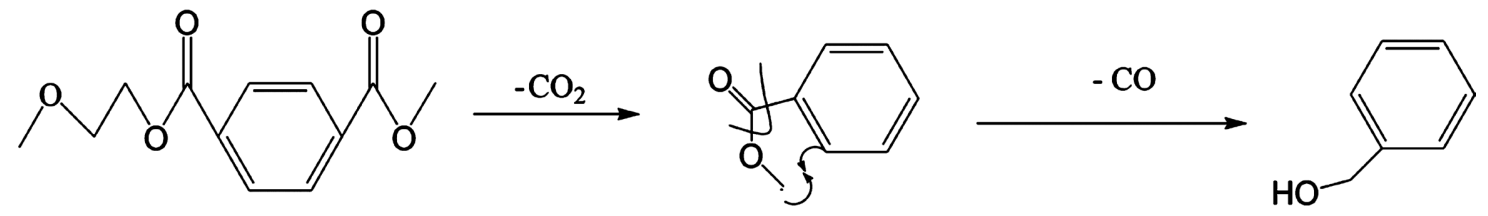

Benzylic alcohol
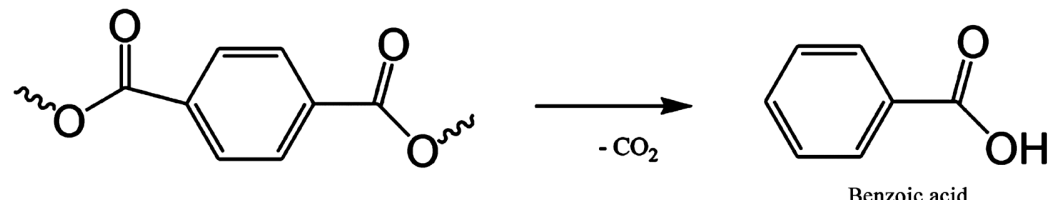

Figure 8. Ester function degradation. 
the other two bonds are flexible and therefore susceptible to being broken easily. This is the reason why the ester bond will be the first to break down. Depending on the degradation Diagram, the products formed will be different, but it will mainly be the breaking of the $\mathrm{C}-\mathrm{O}$ bond which will initiate the degradation when this function is present in the polymer chain. The appearance of benzaldehyde (Figure 9) is the result of a split in the carbonyl function and a release of $\mathrm{CO}_{2}$.

Homolytic cuts can be the origin of rearrangements, revealing acetic acid (Figure 10).

The presence of phthalic anhydride (Figure 11) can have several origins: it can come from the rest of the monomer (formation of the PEI), but also come from a homolytic scission (cleavage of the covalent bond in its middle) followed by a rearrangement.

Ethyl isocyanate can be derived from a Retro-Diels-Alder type degradation of Tris (2-Hydroxyethyl) Isocyanurate (THEIC) (Figure 12).

Styrene formation (Figure 13) follows a double degassing of $\mathrm{CO}_{2}$. It's also a Retro-Diels-Alder type reaction. The double bonds formed in this case are

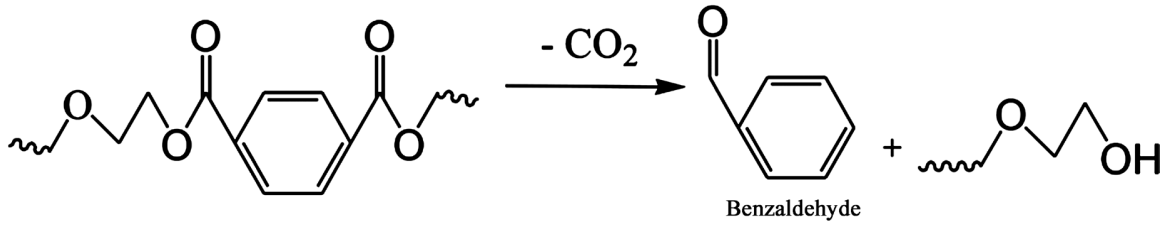

Figure 9. Benzaldehyde formation.
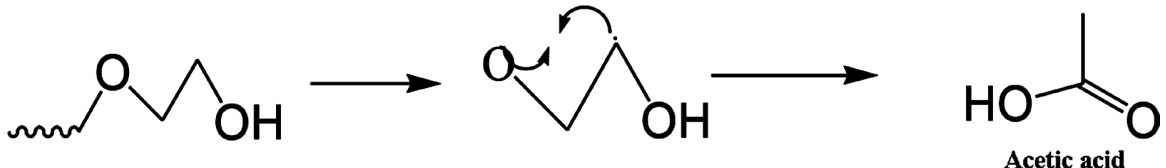

Figure 10. Acetic acid formation.<smiles>COCCOC(=O)c1ccc(OC(=O)c2ccc(C(=O)OC3CO3)cc2)cc1</smiles>

Figure 11. Phthalic anhydride formation.<smiles>CCN(C=O)CCOCCn1c(=O)n(CCO)c(=O)n(CCOC)c1=O</smiles>

Figure 12. THEIC degradation. 
responsible for some of the $\mathrm{CO}_{2}$.

Compounds like aniline [13] [14] and p-amino toluene can come from the same decomposition (Figure 14). The channel splits just didn't happen in the same place.

Phenyl isocyanate (Figure 15) is formed by removal of CO followed by homolytic disruption at the other carbonyl-ring bond. This mechanism was proposed by Krasnov [15]. Only Oksent'evich [16] demonstrated the formation of isocyanate structures. However, the treatment temperatures in his study were significantly higher $\left(710^{\circ} \mathrm{C}\right.$ and $\left.760^{\circ} \mathrm{C}\right)$.

Various authors [17] [18] [19] [20] postulate the existence of a degradation mechanism through an isoimide form. The arguments in favor of such a hypothesis were provided by Gay [19]. His study showed a balance between the

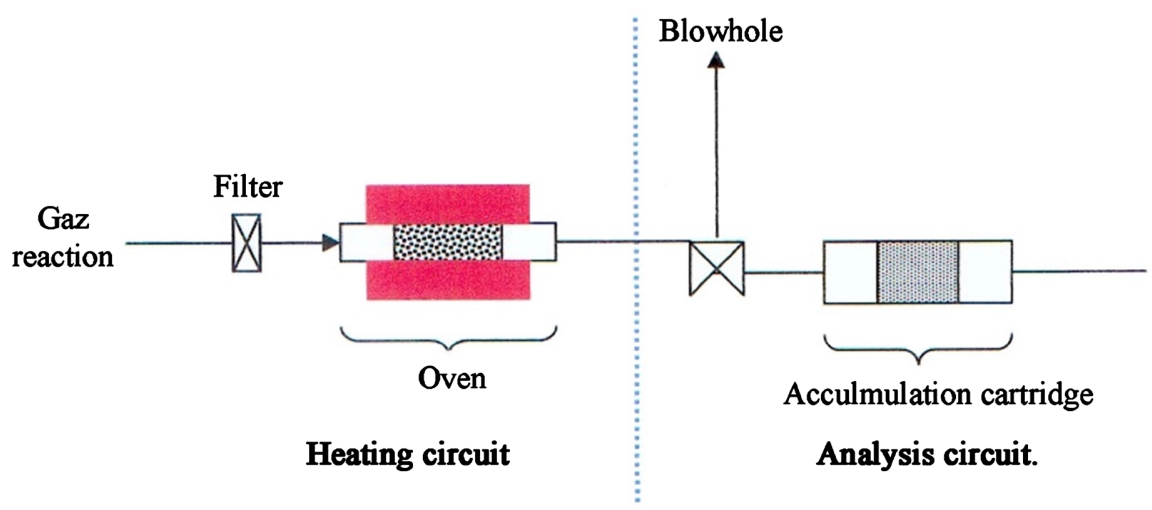

Figure 13. Styrene formation.
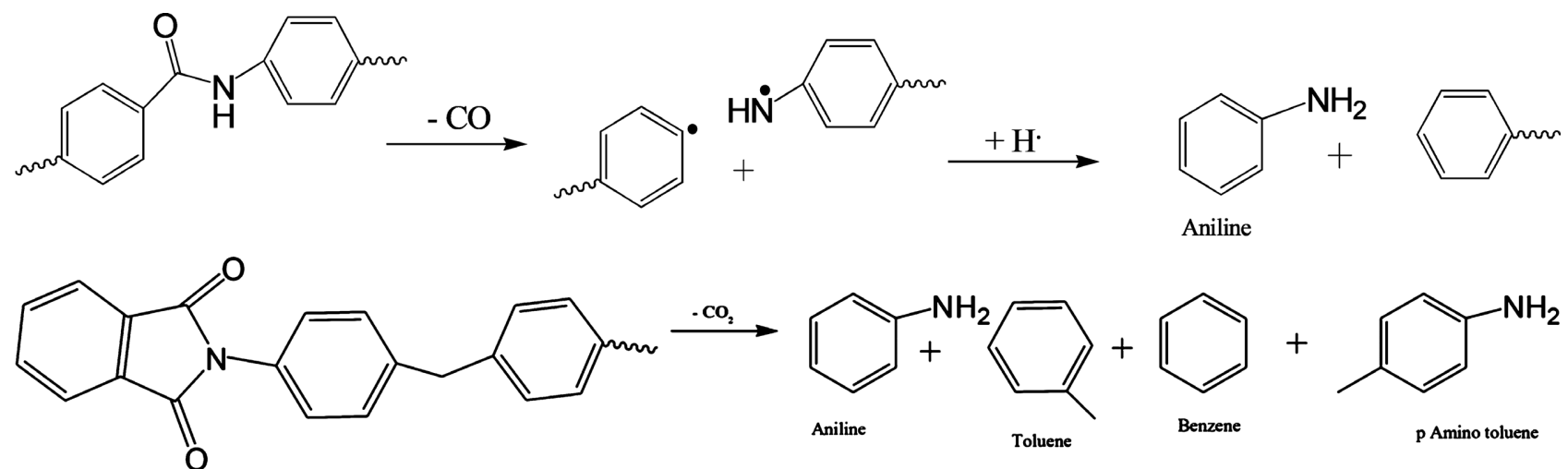

Figure 14. Aniline and p-amino toluene formation.

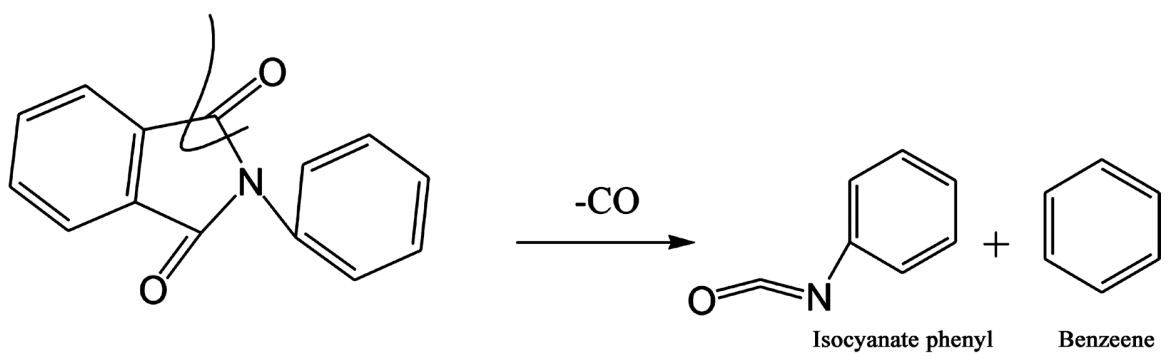

Figure 15. Phenyl isocyanate by decorbonylation formation. 
imide/isoimide forms (Figure 16).

This equilibrium, with the release of $\mathrm{CO}_{2}$, may be one of the origins of the formation of benzonitrile (Figure 17). In addition, it can also be the source of the formation of part of benzoic acid.

This reaction is limited because isoimide being less stable than imide [21], the formation of isoimide is very poor. For this reason, Zurakowska-Orszagh recommends switching to the phthalimide form (Figure 18) before obtaining benzonitrile.

Some of these compounds (benzonitrile and benzoic acid) can also come from the degradation of residual amide-acid species according to the following mechanism (Figure 19).

Thanks to a rearrangement, methyl benzonitrile can be formed (Figure 20) according to the same degradation scheme on the imide part, but considering a rearrangement in the ester part of the PEI.

The isomers of benzene di-carbonitrile (Figure 21) can be derived from several degradation mechanisms, in particular thanks to the tautomeric amide/ imidol balance (Figure 22). Tautomerism is dynamic isomerism (same empirical formula, but different semi-structural or structural formulas). The migration of the hydrogen atom can thus create different structures in equilibrium.<smiles>Cc1ccc(N=C2OC(=O)c3cc(C)ccc32)cc1</smiles>

Figure 16. Imide iso-imide balance.
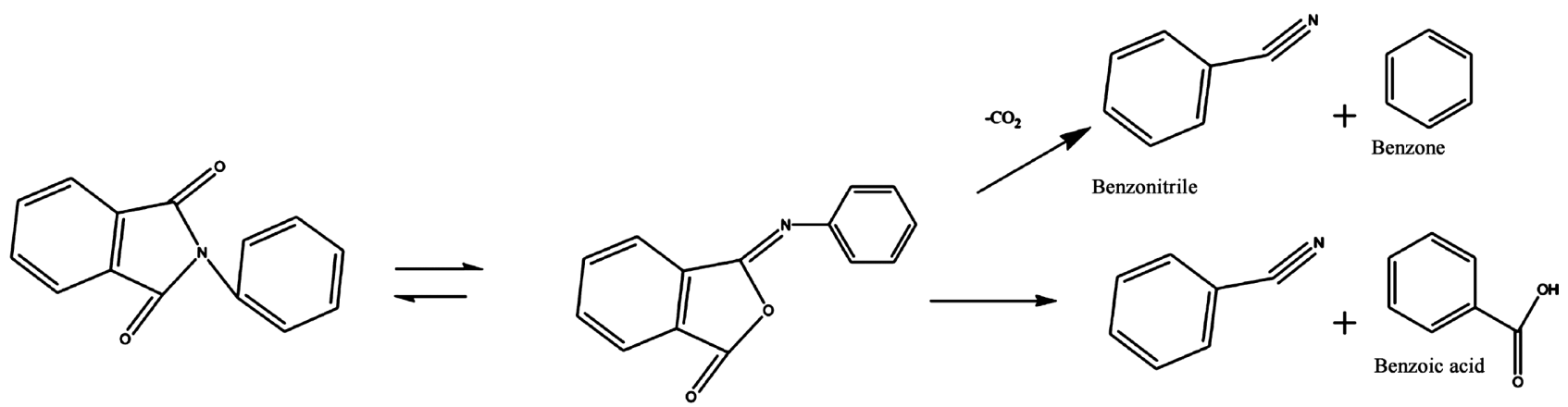

Figure 17. Benzonitril formation.

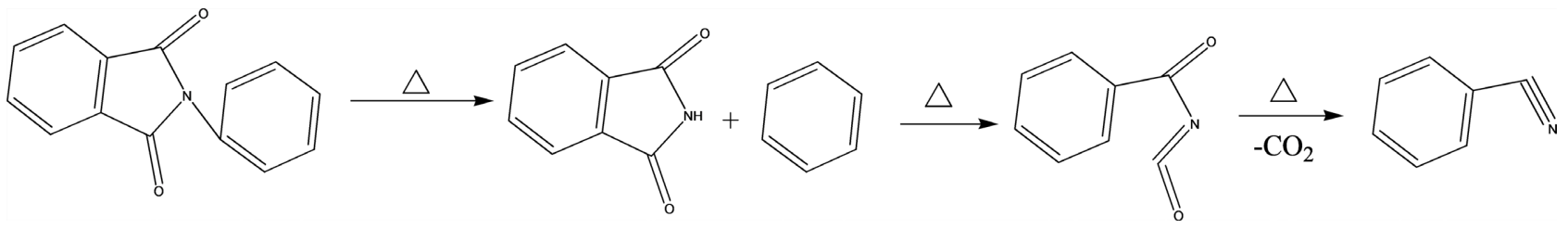

Figure 18. Benzonitrile formation. 


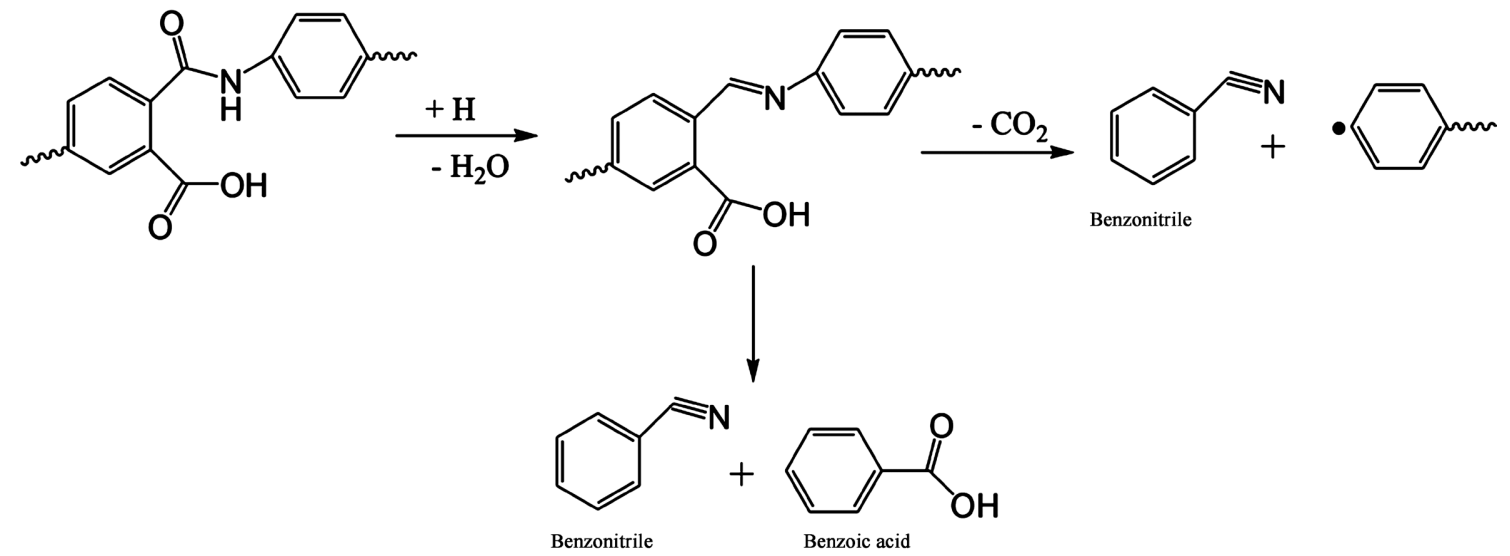

Figure 19. Acid amide residues degradation.
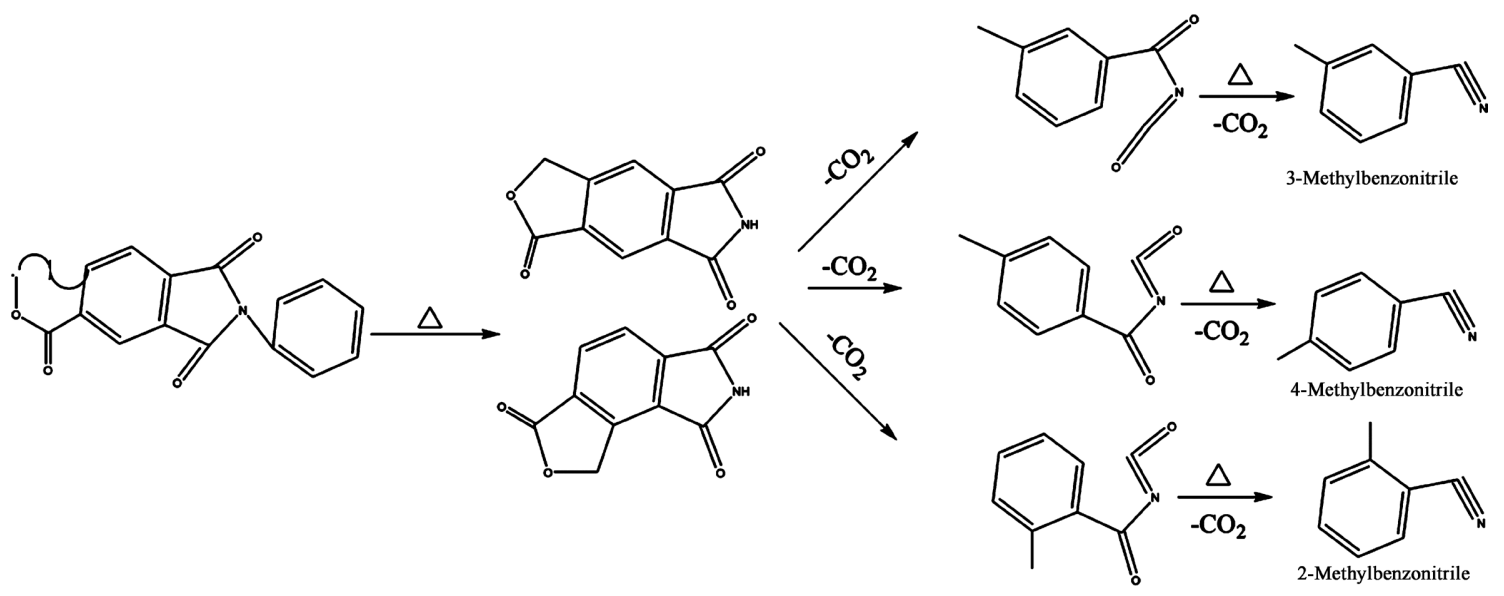

Figure 20. Methylbenzonitril formation.

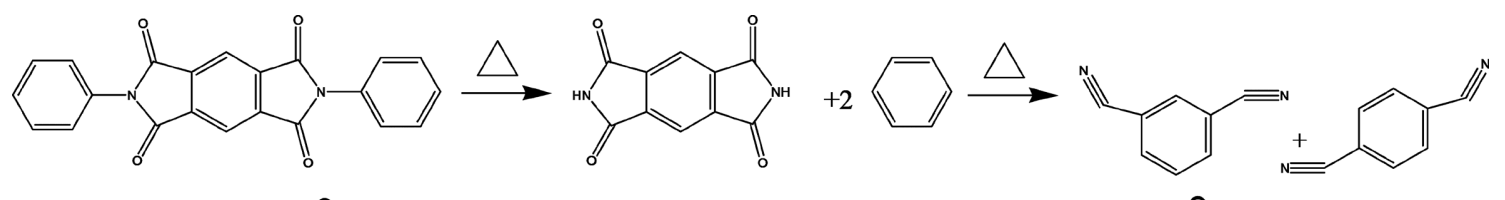

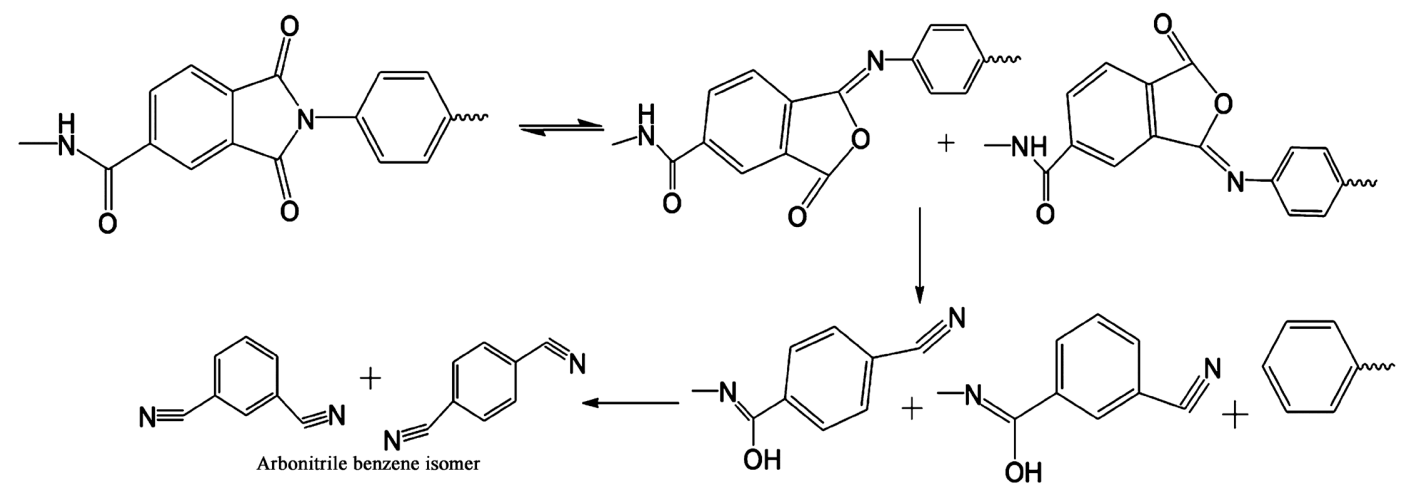<smiles>N#Cc1cccc(C=N)c1</smiles>

Figure 21. Isomeric benzene di-carbonitrile formation. 
Diphenyl methane comes from the cleavage of N-C bonds (Figure 23) probably from PAI. This compound is detected at high temperatures, where, according to ATG measurements, no PEI remains. The $\mathrm{N}-\mathrm{C}$ bond $(305 \mathrm{~kJ} / \mathrm{mol})$ being weaker than the $\mathrm{C}-\mathrm{C}$ bond $(348 \mathrm{~kJ} / \mathrm{mol})$, there is preferential appearance of diphenyl methane.

\subsection{With Oxygen}

The presence of oxygen (analysis in air) is unfavorable to thermal stability. Indeed, even if we have not observed a drop in temperature of the degradation threshold, the fact remains that the degradation kinetics are much faster in an oxidizing medium. The main compounds appearing in air are collated in Table 2. Some degradation products are identical to those obtained in an inert medium.

Their degradation patterns will therefore be identical and will not be reported below. This is the case of toluene (Figure 7), benzyl alcohol, benzoic acid (Figure 8), benzaldehyde (Figure 9), acetic acid (Figure 10), phthalic anhydride (Figure 11), benzonitrile (Figure 18) and benzenedicarbonitrile (Figure 21).

Atmospheric oxygen may not participate directly in the decarbonylation of imide structures. Its action would rather be an indirect effect of embrittlement by oxidation of the polymer chain, the latter leading to the degradation and destruction of the material [22].

Kavarskii [20] involves peroxidic structures; he shown the influence of oxygen on degradation. The intrusion of oxygen can lead to the appearance of degradation products such as p-benzoquinone (Figure 24) or phenol and phenyl isocyanate (Figure 25) depending on the location of oxygen attack.

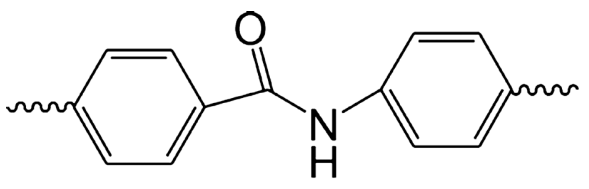

Amid

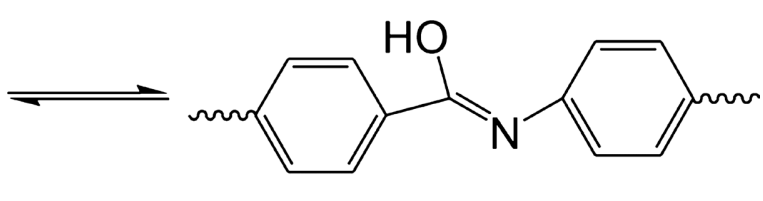

Imidol

Figure 22. Amide/imidol balance.
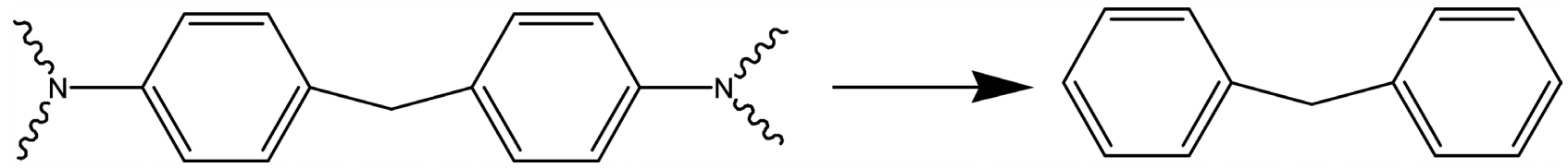

Figure 23. Diphenyl methane formation.

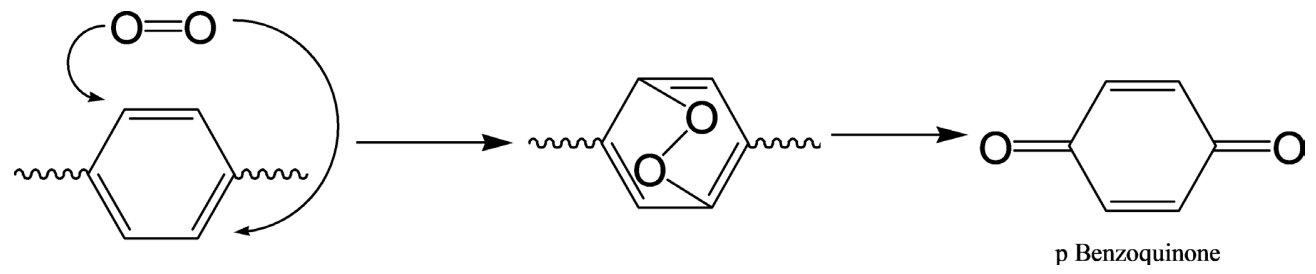

Figure 24. Aromatic cycle degradation by oxygen. 
Temperature is responsible for the loss of a hydrogen atom in the methylene group. In the presence of oxygen, it oxidizes to hydroperoxide [23]. This hydroperoxide can then degrade to give a phenol and a benzaldehyde (Figure 26).

The toluene formed will oxidize to form benzoic acid (Figure 27). This is the reason why it is not detected during the analysis carried out in air.

Acetonitrile is the decomposition product of THEIC with temperature (Figure 28). This reaction is a homolytic decomposition reaction followed by recombination.

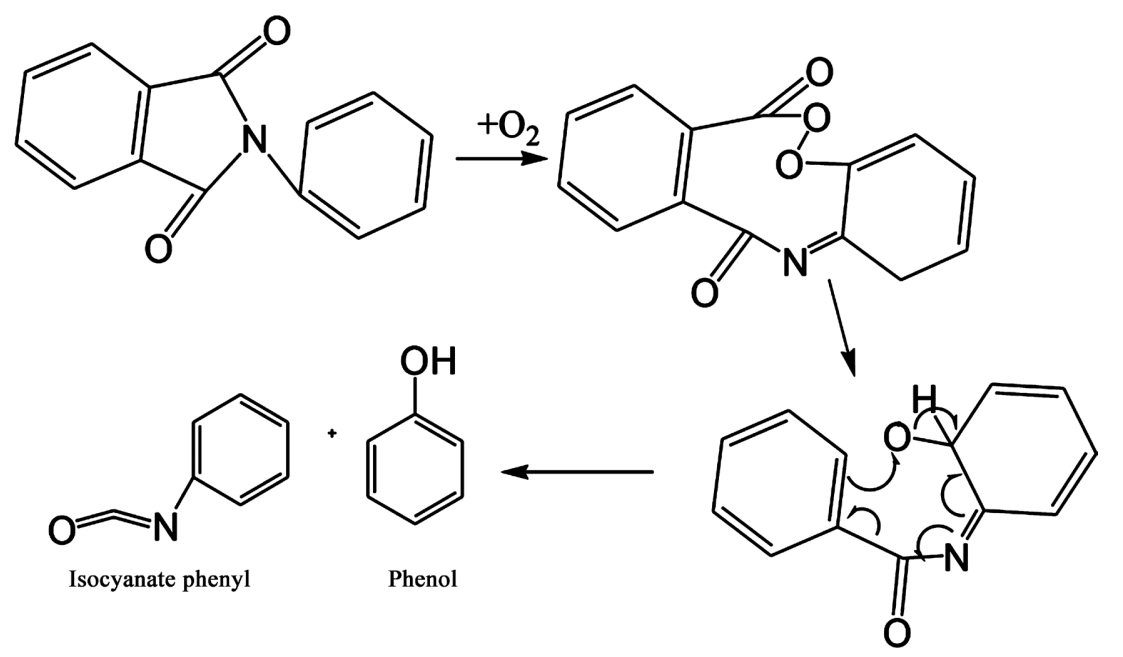

Figure 25. Imide function degradation by oxygen.

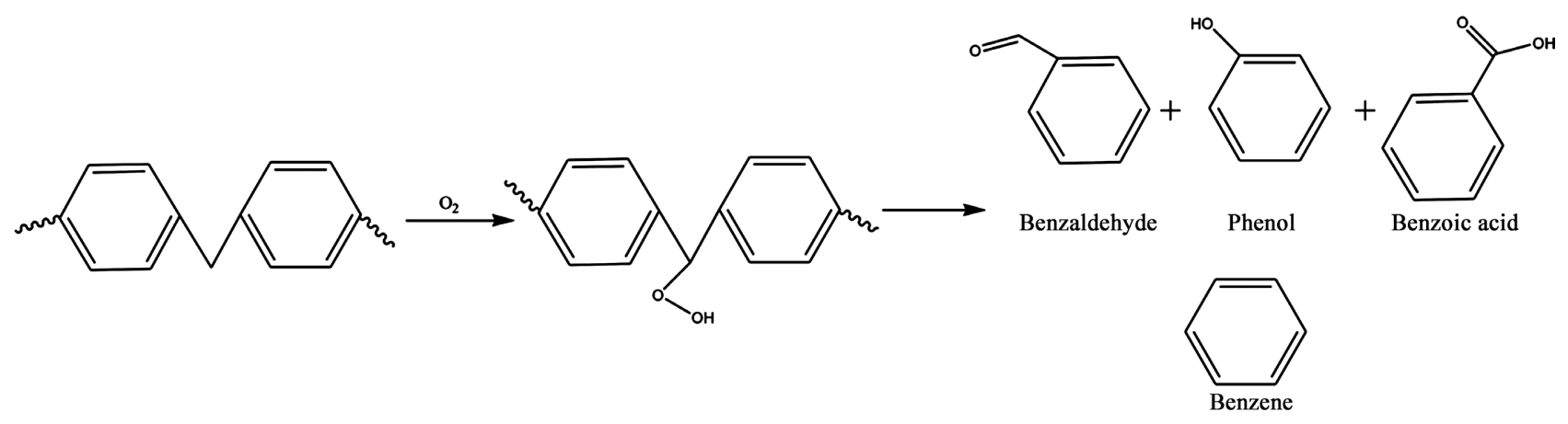

Figure 26. Methylene degradation.
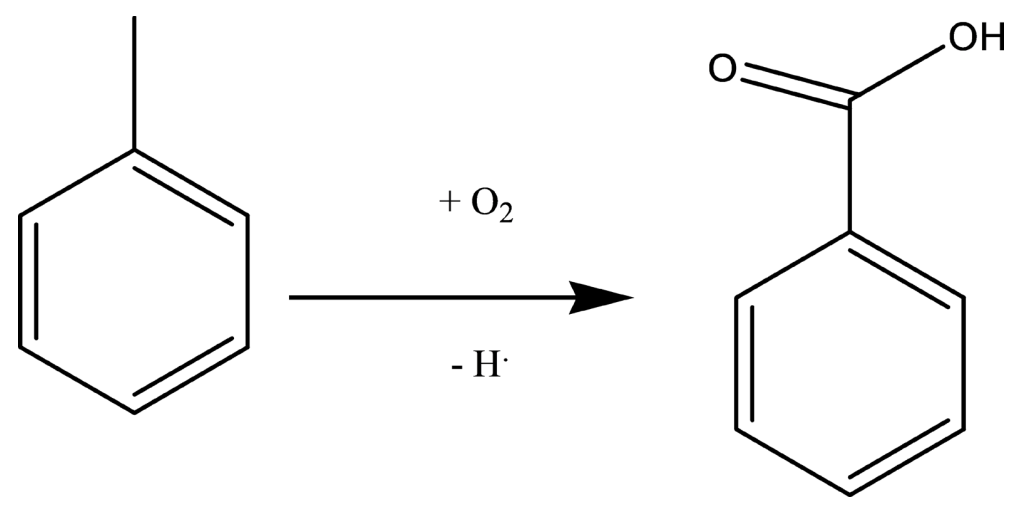

Figure 27. Toluene oxidation. 
Some decomposition mechanisms have revealed a release of $\mathrm{CO}_{2}$ during the degradation of the initial compounds. We have shown the formation of $\mathrm{CO}_{2}$ by an experiment involving lime water (Figure 29).

This experiment is classic for the detection of $\mathrm{CO}_{2}$ : lime water indeed has the particularity of becoming cloudy in the presence of $\mathrm{CO}_{2}$. This cloudiness results from the formation of calcium carbonate (Figure 30), a white precipitate insoluble in water.

To perform this experiment, pieces of PAI/PEI were peeled off the plates and then placed in an oven with circulating nitrogen. The nitrogen sweep is passed through a lime water solution. Due to the release of $\mathrm{CO}_{2}$ during degradation, the lime water became cloudy, thus proving its formation. This experiment makes it possible to validate the proposed degradation schemes.

The identification of the different degradation products as well as their different thresholds of appearance will allow us to select a compound that can be used as a chemical tracer of the state of degradation of the insulation system. This check also makes it possible to determine whether an engine has transiently had to undergo temperatures above its thermal class, provided that the gases remain trapped.

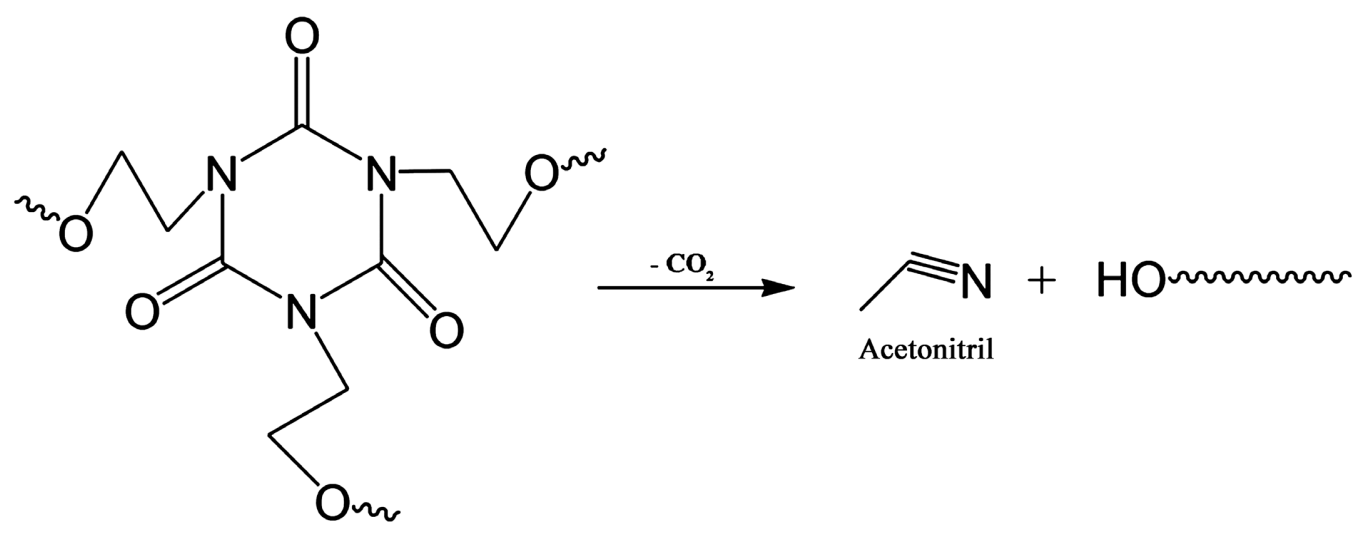

Figure 28. THEIC decomposition diagram.

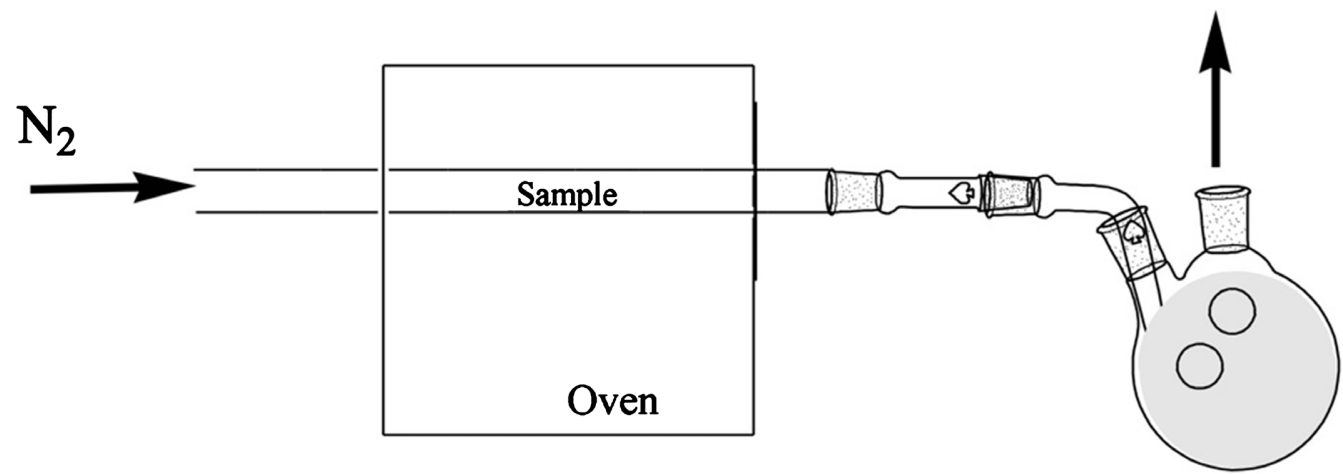

Figure 29. Schematic diagram of the experiment with lime water.

$$
\mathrm{Ca}(\mathrm{OH})_{2}+\mathrm{CO}_{2} \rightarrow \mathrm{CaCO}_{3}+\mathrm{H}_{2} \mathrm{O}
$$

Figure 30. Reaction of carbon dioxide with lime water. 


\section{Proposal for Selection and/or Means of Observing Degradation Process}

The only products likely to be suitable for monitoring degradation are those resulting from decomposition mechanisms in the presence of oxygen. The product must also be easily identifiable. In addition, it must be one of the first products to appear during degradation in order to prevent failure. Finally, it must be available in sufficient quantity to be detectable. Of the degradation products mentioned in Figure 6, benzaldehyde and benzoic acid appear to be the best candidates. We will therefore review the different means of detecting these two molecules. Benzaldehyde is found in liquid form (colorless liquid) at room temperature (its melting point is $-26^{\circ} \mathrm{C}$ ). Benzaldehyde gas can be captured by a solid adsorbent (silica, octadecyl grafted silica or XAD2 resin) impregnated with a derivatization agent (2,4dinitrophenylhydrazine or 2-hydromethylpiperidine). Benzaldehyde vapors are trapped on the cartridge in derivative form. The cartridge is then desorbed by entraining the products with acetonitrile (cartridge impregnated with DNPH) or brought into contact with toluene and stirred with ultrasound (cartridge impregnated with 2-hydromethylpiperidine).

Another solution consists in trapping the benzaldehyde directly on a solid polyphase adsorbent (carbopack/carboxen). Desorption then takes place thermally under the influence of inert gas (helium). The analysis of the extracts is finally carried out by HPLC (C18 or Zorbax ODS column with an acetonitrile/water mobile phase gradient) coupled to a UV/visible detector, operating at a wavelength of $360 \mathrm{~nm}$. Benzoic acid can be recovered by cooling the air because it is in the solid form (white solid) at room temperature (its melting point is $122^{\circ} \mathrm{C}$ ). It can also be adsorbed by silica (solid adsorbent). Benzoic acid can be analyzed by column HPLC (C18 with an acetate/acetonitrile 80/20 buffer mixture) coupled to a UV/visible detector operating at a wavelength of $254 \mathrm{~nm}$.

Both benzoic acid and benzaldehyde are compounds that absorb UV radiation at different wavelengths, and can also be recovered in the same way (silica adsorbent). Due to their abundance and their modes of identification, they are therefore both likely to provide a tracer on the state of degradation of the electrical insulation. The difficulty lies in the capture (trapping of these molecules). In a closed rotating machine, as is the case with safety engines, it is necessary to provide access to the interior of the engine in order to take a gas sample.

\section{Conclusion}

A new method to detect thermal degradation in the primary insulation of rotating machines working temporarily at high temperatures (up to $400^{\circ} \mathrm{C}$ ) has been proposed in this article. It consists in detecting the products resulting from the degradation of the insulation under the effect of temperature. The coupling between chromatographic and mass spectroscopy measurements has, for this purpose, been carried out under an oxidizing and inert atmosphere. The analysis of these measurements allowed us to identify the various products resulting from 
the degradation of the initial material as well as their thresholds of appearances. Under air, a shift of these thresholds towards low temperatures was naturally observed. The information extracted from these measurements enabled us to propose preferential degradation schemes for each type of environment, thus allowing a better understanding of the degradation processes of these materials. To be easily detectable, the decomposition material(s) which will have to be looked for are naturally which will be released in large quantities. In addition, for effective prediction, this or these compound(s) must be the first to be released. Our analyses showed that benzaldehyde and benzoic acid were the compounds that best met all of these criteria. The first can be captured by a cartridge having a solid adsorbent (silica) impregnated with a bypassing agent. The cartridge can then be desorbed in different ways: contact with a reagent, thermal method, etc. The second can also be captured by a solid adsorbent (silica) but also recovered by cooling (the latter being solid at room temperature). These two compounds absorb UV radiation at different wavelengths and could therefore be detected by illumination on an adsorbent. Regardless of the compound selected for the detection of the onset of degradation of the electrical insulation, it will be necessary to provide a device in the design of the motor to allow it to be sampled. At hightemperature, closing motors safely and confining this product inside the machine will make it easier to capture.

\section{Acknowledgments}

The authors would like to thank NIDEC-Leroy Somer Company for funding this study. They would also like to thank Anne GIMENEZ, François PELTIER and Jacques SAINT-MICHEL for their help through fruitful discussion.

\section{Conflicts of Interest}

The authors declare no conflicts of interest regarding the publication of this paper.

\section{References}

[1] Aymonino, F., Lebey, T., Malec, D., Petit, C., Saint-Michel, J., Anton, A. and Gimenez, A. (2006) Dielectric Measurements of Rotating Machines Insulation at High Temperatures $\left(200-400^{\circ} \mathrm{C}\right)$. Proceeding of the IEEE Conference on Solid Dielectrics, Kansas City, 15-18 October 2006, 740-743. https://doi.org/10.1109/CEIDP.2006.312038

[2] Aymonino, F., Lebey, T., Malec, D., Petit, C., Saint-Michel, J., Anton, A. and Gimenez, A. (2007) Degradation and Dielectric Measurements of Rotating Machines Insulation at High Temperatures $\left(200-400^{\circ} \mathrm{C}\right)$. Proceeding of the IEEE Conference on Solid Dielectrics, Winchester, 8-13 July 2007, 130-133. https://doi.org/10.1109/ICSD.2007.4290770

[3] Courvoisier, E., Bicaba, Y. and Colin, X. (2018) Analyse de la degradation thermique du Poly(éther imide). Matériaux \& Techniques, 105, 402-415. https://doi.org/10.1051/mattech/2018006

[4] Courvoisier, E., Bicaba, Y. and Colin, X. (2018) Multi-Scale and Multi-Technical Analy- 
sis of the Thermal Degradation of Poly(Ether Imide). Polymer Degradation and Stability, 147, 177-186. https://doi.org/10.1016/j.polymdegradstab.2017.12.002

[5] Carroccio, S., Puglisi, C. and Montaudo, G. (1999) Thermal Degradation Mechanisms of Polyetherimide Investigated by Direct Pyrolysis Mass Spectrometry. Macromolecular Chemistry and Physics, 200, 2345-2355.

https://doi.org/10.1002/(SICI)1521-3935(19991001)200:10<2345::AID-MACP2345> 3.0.CO;2-T

[6] Perng, L.H. (2000) Thermal Decomposition Characteristics of Poly(ether imide) by TG/MS. Journal of Polymer Research, 3, 185-193.

https://doi.org/10.1007/s10965-006-0119-7

[7] Shi, G., Baeck, K., Bae, J. and Park, L.S. (2020) Acidic Polyester Imides as Thermally Stable Binder Polymers for Negative-Tone Black Photoresist. Material Sciences and Applications, 11, 234-244. https://doi.org/10.4236/msa.2020.114016

[8] Sumislawska, M. and Gyftakis, K.N. (2016) The Impact of Thermal Degradation on Properties of Electrical Machine Windings Insulation Material. IEEE Transactions on Industry Applications, 52, 2951-2960. https://doi.org/10.1109/TIA.2016.2544745

[9] Gornicka, B. and Gorecki, L. (2010) TGA/DTG/DSC Investigation of Thermal Ageing Effects on Polyamide-Imide Enamel. Journal of Thermal Analysis and Calorimetry, 101, 647-650. https://doi.org/10.1007/s10973-010-0883-9

[10] Petitgas, B., Seytre, G., Gain, O., Boiteux, G., Royaud, I., Serghei, A., Gimenez, A. and Anton, A. (2011) High Temperature Aging of Enameled Copper Wire. Relationships between Chemical Structure and Electrical Behavior. Annual Report on the IEEE Conference on Electrical Insulation and Dielectric Phenomena, Cancun, 16-19 October 2011, 84-88. https://doi.org/10.1109/CEIDP.2011.6232602

[11] Kavanagh, D., Gyftakis, K.N. and Culloch, M.D.M. (2020) Thermal Degradation Phenomena of Polymer Film on Magnet Wire for Electromagnetic Coils. IEEE Transactions on Industry Applications, 57, 458-467. https://doi.org/10.1109/TIA.2020.3040201

[12] Anton, A. (2009) Insulating Enamels and Enameled Wires. Techniques de l'Ingénieur, d2330. https://doi.org/10.51257/a-v1-d2330

[13] Ehlers, G.F.L., Fish, K.R. and Powell, W.R. (1970) Thermal Degradation of Polymers with Phenylene Units in the Chain IV Aromatic Polyamides and Polyimides. Journal of Polymer Science, 8, 3511-3527. https://doi.org/10.1002/pol.1970.150081213

[14] Brown, J.R. and Power, A.J. (1982) Thermal Degradation of Aramids: Part I Pyrolysis/Gas Chromatography/Mass Spectroscopy of Poly(1,3-Phenylene Isophtalamide) and Poly(1,4-Phenylene Terephtalamide). Polymer Degradation and Stability, 4, 379392. https://doi.org/10.1016/0141-3910(82)90044-1

[15] Krasnov, Y.P., Aksenova, V.P., Krar'kov, S.N. and Baranova, S.A. (1970) Mechanism of Thermal Degradation of Aromatic Polyimides with Different Chemical Structures. Polymer Science USSR, 12, 989-1003. https://doi.org/10.1016/0032-3950(70)90395-3

[16] Oksent'Evich, L.A., Badyeva, M.M., Tuleninova, G.I. and Pravedikov, A.N. (1977) The Thermal Degradation Mechanism of Models Compounds of Aromatic Polymides. Polymer Science USSR, 19, 637-645. https://doi.org/10.1016/0032-3950(77)90121-6

[17] Rode, V.V., Gribkova, P.N., Vygodskii, Y.S., Vinogradova, S.V. and Korshak, V.V. (1968) Influence of Aramide Groups as Links in Polyimides in Their Thermal Stability. Polymer Science USSR, 10, 1780-1787. https://doi.org/10.1016/0032-3950(70)90323-0 
[18] Gribkova, P.N., Rode, V.V., Vygodskii, Y.S., Vinogradova, S.V. and Korshak, V.V. (1970) Degradation of Aromatic Polymides at High Temperature. Polymer Science USSR, 12, 252-263. https://doi.org/10.1016/0032-3950(70)90299-6

[19] Gay, F.P. and Berr, C.E. (1968) Polypyromellitimides: Details of Pyrolysis. Journal of Polymer Science: Polymer Chemistry Edition, 6, 1935-1943.

https://doi.org/10.1002/pol.1968.150060715

[20] Kovarskii, M., Annekova, N.G., Gur'yanova, A.B. and Bluyumenfel'd, A.B. (1973) The Mechanism of Oxidation of Polyimides. Polymer Science USSR, 1, 2783-2790. https://doi.org/10.1016/0032-3950(73)90333-X

[21] Zurakowska-Orszagh, J., Cheptowicz, T., Orzesko, A. and Kaminski, J. (1979) Thermal Degradation of Polyimides-I-Investigation of the Role of Isoimide Structure on Degradation Process. European Polymer Journal, 15, 409-413.

https://doi.org/10.1016/0014-3057(79)90162-9

[22] Dutruch, L. (1996) Etude de la reticulation, du vieillissement et de la degradation thermique de bisnadimides: couplage analyse thermo-gravimétrique-chromatographie en phase gazeuse. Ph.D. Thesis, Université Claude Bernard, Lyon.

[23] Sagnier, C. (1995) Polyimide-amides-Polycondensation avec les diisocyanates: Microstuctures-mécanismes de formation-Mécanismes de degradation thermo-oxydante. Ph.D. Thesis, Université Claude Bernard, Lyon. 